УДК 342.5

\title{
А.С. Давиденко
}

Владивостокский государственный университет экономики и сервиса

Владивосток. Россия

\section{Концепция электронного правительства и цифровизация политической системы}

В настоящей статье рассмотрена специфика модели электронного правительства, функционирующего на территории российского государства, включая отдельные аспекты его становления и развития, инфраструктурные компоненты, в том числе каналы электронного доступа к получению государственных и муниципальных услуг, единая система идентификации и аутентификации (ЕСИА), единая система межведомственного электронного взаимодействия (СМЭВ), государственная информационная система о государственных и муниципальных платежах, федеральный реестр государственных и муниципальных услуг (функций) (ФРГУ), информационно-аналитическая система мониторинга качества государственных услуг. Автором делается вывод о существовании отдельных проблем практической реализации электронного правительства в России и необходимости их разрешения, а также предлагается собственное видение преодоления и устранения выявленных проблем в правоприменительной практике.

Ключевые слова и словосочетания: электронное правительство, государственные услуги, правовое регулирование процессов информатизации деятельности государственных органов власти.

\section{A.S. Davidenko}

Vladivostok State University of Economics and Service

Vladivostok. Russia

\section{E-government concept and digitalization of the political system}

This article examines the specifics of the e-government model operating on the territory of the Russian state, including certain aspects of its formation and development, infrastructure components: including channels of electronic access to receiving state and municipal services., a unified system of identification and authentication (ESIA), a unified system of interdepartmental electronic interaction (SMEV), the state information system about state and municipal payments, the federal register of state and municipal services (functions) (FRGU),

Давиденко Алексей Сергеевич - магистрант Института права; e-mail: davidenko@list.ru 30 
an information and analytical system for monitoring the quality of public services. The author draws a conclusion about the existence of certain problems of the practical implementation of electronic government in Russia and the need to resolve them, and also proposes his own vision of overcoming and eliminating the identified problems in law enforcement practice.

Keywords: e-government, public services, legal regulation of the processes of Informatization of the activities of state authorities.

Актуальность выбранной темы исследования. В конце XX века широкое распространение во всех сферах жизнедеятельности государств мира и их населения получили информационные технологии, функционирующие на базе телекоммуникационной сети Интернет. Они быстро стали массово доступны пользователям ввиду их относительно низкой стоимости, что не могло не быть учтено руководящими структурами и взято на заметку для целей государственного управления: они получили собственное определение при использовании в данном направлении и стали именоваться «e-government»- электронное правительство. По определению Организации Объединенных Нации, «e-government»- это «...применение правительствами различных стран информационно-коммуникационных технологий для преобразования своих внутренних и внешних взаимоотношений...» [1].

Актуальность исследования обусловлена повсеместным применением моделей электронного правительства в различных государствах мира, включая Российскую Федерацию, где их использование не проходит беспроблемно. Иными словами, научное осмысление выбранной темы будет способствовать поиску путей преодоления существующих сложностей в функционировании российской модели электронного правительства. Объект исследования - общественные отношения, формирующиеся в результате применения информационных технологий для получения государственных и муниципальных услуг. Предмет исследования, в свою очередь, охватывает действующие нормативные правовые акты, регламентирующие данный вопрос, соответствующие материалы сформированной практики, а также научные изыскания по выбранной теме.

Цель и задачи настоящего исследования. Главная цель проведения комплексного, всестороннего и детального анализа особенностей российской модели электронного правительства заключается в выявлении проблем, которые возникают при ее применении, а также в разработке собственного авторского взгляда на разрешение данных проблем, способов их устранения и преодоления.

Достижение поставленной цели стало возможным за счет последовательного решения следующих задач:

- анализ нормативно-правовой базы российской модели электронного правительства;

- изучение особенностей, свойственных российской модели электронного правительства;

- выявление имеющихся сложностей в практической реализации концепции электронного правительства на территории российского государства; 
- разработка и предложение к внедрению собственных путей решения проблем практической реализации концепции электронного правительства на территории российского государства.

Особенности российской модели электронного правительства. Переходя к рассмотрению вопроса об особенностях модели «электронного правительства», функционирующего на территории российского государства, следует отметить, что история его становления началась с принятия в 2002 году федеральной целевой программы «Электронная Россия (2002-2010 годы») [2] и продолжается по сей день уже в рамках практической реализации другой федеральной целевой программы, получившей название «Информационное общество (2011-2020 годы)» [3]. Центральным и основополагающим направлением данных программ стало получение гражданами государственных и муниципальных услуг в электронной форме посредством использования специально разработанных информационно-коммуникативных технологий.

По состоянию на 2020 год отечественным законодателем был принят ряд нормативных правовых актов, положения которых призваны урегулировать различные вопросы, сопряженные с функционированием электронного правительства в России, включая следующие федеральные и подзаконные акты:

1) Ф3 «Об информации, информационных технологиях и о защите информации» от 27.07.2006 г. № 149-Ф3 [4];

2) Ф3 «Об организации предоставления государственных и муниципальных услуг» от 27.07.2010 г. № 210-Ф3 [5];

3) Ф3 «О персональных данных» от 27.07.2006 г. № 152-Ф3 [6];

4) Ф3 «Об электронной подписи» от 06.04.2011 г. № 63-Ф3 [7];

5) Указ Президента РФ «Об основных направлениях совершенствования системы государственного управления» от 12.05.2012 г. № 601 [8];

6) Постановление Правительства РФ «Об утверждении государственной программы Российской Федерации «Информационное общество (2011-2020 годы)» от 15.04.2014 г. № 313 [9];

7) Распоряжение Правительства РФ «О Концепции развития механизмов предоставления государственных и муниципальных услуг в электронном виде» от 25.12.2013 г. № 2516-р [10];

8) Постановление Правительства РФ «О требованиях к предоставлению в электронной форме государственных и муниципальных услуг» от 26.03.2016 г. № 236 [11].

На современном этапе в структурном выражении российская модель электронного правительства представлена следующими инфраструктурными элементами, в полной мере позволяющими обеспечить реализацию предоставления гражданам государственных и муниципальных услуг в интерактивной форме:

1. Каналь электронного доступа к получению государственных и муниииnальных услуг. Прежде всего, речь идет о Едином портале государственных и муниципальных услуг (ЕПГУ, Госуслуги), а также о различных региональных порталах государственных и муниципальных услуг (далее - РПГУ), которые на сегодняшний день действуют практически в каждом субъекте российского госу- 
дарства. Кроме того, к таким каналам относятся и официальные сайты, порталы органов государственной и муниципальной власти, а также их версии в виде приложений для средств телефонной связи, в том числе базирующихся на различных операционных системах (iOS, Android).

2. Единая система идентификации и аутентификаиии (ЕСИА). Данный элемент обеспечивает реальную возможность использования одного и того же идентификатора личности человека для получения им доступа к электронным государственным и муниципальным услугам, которые оказываются, предоставляются различными поставщиками, в том числе и через различные информационно-телекоммуникационные каналы связи.

3. Единая система межведомственного электронного взаимодействия (СМЭВ). Обозначенный элемент призван обеспечить граждан эффективным, результативным и своевременным взаимодействием органов государственной и муниципальной власти при оказании государственных и муниципальных услуг в электронной форме. Другими словами, фактически он создан для быстрого и оперативного обмена важной правовой информацией.

4. Государственная информационная система о государственных и мунициnальных платежах. Указанный элемент позволяет как физическим, так и юридическим лицам оперативно, максимально быстро получать необходимую информацию об их обязательствах перед бюджетом российского государства, региональным бюджетом, муниципальным бюджетом при действии такого основополагающего принципа, как «единое окно», а также осуществлять учет платежей, начислений при оказании различных государственных и муниципальных услуг в электронной форме.

5. Федеральный реестр государственных и муниципальных услуг (функиий) (ФРГУ). Обозначенный элемент призван в течение длительного периода сохранять существующую информацию о всех государственных и муниципальных услугах (в том числе, информацию о списке требуемых документов для их получения, поставщике, сроках оказания, а также о результатах предоставления).

6. Информационно-аналитическая система мониторинга качества государственных услуг. Данный элемент российской модели электронного правительства представляет собой площадку, обеспечивающую доступ к собранной, обработанной и проанализированной информации о качестве предоставления услуг органами государственной власти, а также органами муниципальной власти. Функционирование этой системы позволяет принимать на высшем уровне решения, связанные с усовершенствованием качества оказываемых услуг.

Функционирование обозначенного комплекса элементов, в совокупности своей составляющих российскую модель электронного правительства, обеспечено быстрым ростом (иногда его отмечают даже поистине взрывным) числа оказываемых услуг в электронной форме органами государственной и муниципальной власти: так, в 2016 году их количество составило более 220 миллионов, а по истечении 2019 года - свыше 350 миллионов [12].

Необходимо обратить внимание, что для обеспечения нормальной работы каждого из названных элементов российского электронного правительства 
к данной системе подключены всевозможные государственные информационные ресурсы, а также двенадцать тысяч организаций, которые принимают участие в предоставлении и оказании гражданам государственных и муниципальных услуг. Кроме того, на современном этапе ведется грамотная, спланированная работа по использованию системы транзакций в процессах реализации государственных и муниципальных функций (по состоянию на начало 2020 года их число составило около 10 млрд) [12].

В инфраструктуре российской модели электронного правительства функционирует также информационная система Головного удостоверяющего центра, которая обеспечивает возможность практического применения электронной подписи при получении государственных и муниципальных услуг, а также предоставляет сервисы доверия в части использования электронных документов, мониторинг и оценку качества услуг, оказываемых региональными удостоверяющими центрами, действующими на территории различных субъектов Российской Федерации. Помимо прочего, с этой целью также был реализован механизм кросс-сертификации и выдачи корневых сертификатов для удостоверяющих центров.

Повышенное внимание было уделено отечественным законодателем и к обеспечению должного уровня прозрачности и открытости деятельности органов государственного и муниципального управления на базе федеральной целевой концепции «Открытое правительство». Перечень информации, которая подлежит раскрытию на официальных сайтах, в строгом соответствии определен положениями Федерального закона «Об обеспечении доступа к информации о деятельности государственных органов и органов местного самоуправления» от 09.02.2009 г. № 8-Ф3.

С 2010 по 2020 год была проведена огромная работа по учреждению и функционированию каналов прямого взаимодействия граждан с руководителями органов государственной власти и органов муниципальной власти. К числу подобного рода информационно-телекоммуникационных каналов правомерно относить различные блоги, ютуб-каналы, сервисы социальных сетей (например, ВКонтакте, Инстаграм и др.).

Реализованы значимые инициативы по вопросам взаимодействия органов государственной власти и органов муниципальной власти с российским населением, а также представителями национального бизнеса. В том числе созданы и по сей день функционируют следующие интерактивные площадки:

1. Портал «Российская общественная инициатива».

2. Портал открытых данных Российской Федерации.

3. Единый портал для размещения информации о подготовке федеральными органами исполнительной власти проектов нормативных правовых актов и результатах их общественного обсуждения.

Проблемы практической реализации концепции электронного правительства на территории российского государства, сложности в его функционировании и способы их преодоления и разрешения. Несмотря на указанные достижения, Россия постоянно сталкивается с рядом неразрешенных проблем и препятствий, которые в значительной степени осложняют функционирова- 
ние российской модели электронного правительства и требуют для своего преодоления и устранения принятия ряда стратегических и тактических решений.

Первая проблема связана с разобщенностью органов государственной и муниципальной власти, дублированием вверенных им полномочий. По сути не всегда понятно, в какой орган надлежит адресовать то или иное заявление. Невозможно уточнить заблаговременно посредством электронного взаимодействия необходимую информацию, что влечет за собой вынесение огромного числа отказных решений по обращениям граждан и, как следствие, усложняет процедуру взаимодействия гражданского общества с властью.

Вторая проблема заключается в отсутствии четко слаженной нормативной правовой базы, содержание которой в полной мере было бы посвящено урегулированию всевозможных вопросов, связанных с функционированием модели электронного правительства на территории российского государства. Вышеназванные акты во многом противоречат друг другу, отчасти не охватывают своими положениями регулирование всех вопросов, связанных с практической реализацией данной концепции в России.

Третья проблема напрямую вытекает из необходимости использования для реализации концепции электронного правительства на территории российского государства исключительно лицензионного программного оборудования, которое отличается высокой стоимостью и требует достаточно большого потока финансирования из государственного бюджета, поскольку иное оборудование небезопасно и некорректно в своем практическом использовании.

Четвертая проблема связана с невозможностью обеспечения в полном объеме кибербезопасности при практической реализации модели электронного правительства на территории российского государства, что способствует утечке конфиденциальной информации и нарушению конституционно провозглашенного права человека на частную жизнь.

И, наконец, пятая из выявленных нами проблем заключается в неправильной организации взаимодействия гражданского общества и властных структур посредством применения электронных технологий: по факту остается достаточно большой процент граждан, которые не понимают и даже боятся применения электронных систем.

Подход к разрешению выявленных проблем, на наш взгляд, должен носить комплексный и всесторонний характер за счет системного и постоянного применения нижеследующей совокупности мер:

1. Формирование спроса на получение электронных услуг у гражданского общества (в частности, за счет проведения просветительской работы средств массовой информации, а также лекционных занятий на базе предприятия).

2. Создание единых стандартов для органов власти по оказанию услуг в электронной форме с четким разграничением полномочий и функций, о чем потребитель таких услуг может быть проконсультирован дистанционно.

3. Внедрение зарубежного опыта по обеспечению кибербезопасности и привлечение для этого дополнительного финансирования. 
Выводы. Несмотря на весомые достижения, Российская Федерация постоянно сталкивается с рядом неразрешенных проблем и препятствий, которые в значительной степени осложняют функционирование российской модели электронного правительства и требуют для своего преодоления и устранения принятия ряда стратегических и тактических мер.

1. Electronic-government. Glossary: [сайт]. - URL: https://www.un.org/en/ - Текст: электронный (дата обращения: 06.09.2020).

2. О федеральной целевой программе «Электронная Россия (2002-2010 годы)»: Постановление Правительства РФ от 28.01.2002 № 65 (ред. от 09.06.2010). - Текст: электронный // СПС «Гарант»: [сайт]. - URL: http://base.garant.ru/184120/ (дата обращения: 06.09.2020).

3. Информационное общество (2011-2020 годы). - Текст: электронный // СПС «КонсультантПлюс»: [сайт]. - URL: http://www.consultant.ru/document/Cons_doc_LAW_ 155198/d60fab9834a8f7ea1bad56bb17af05751937b2a3/ (дата обращения: 06.09.2020).

4. Об информации, информационных технологиях и о защите информации: федеральный закон от 27.07.2006 г. № 149-Ф3 (посл. ред. от 03.04.2020). - Текст: электронный // CПС «КонсультантПлюс»: [сайт]. - URL: http://www.consultant.ru/document/cons_doc_ LAW_61798/ (дата обращения: 06.09.2020).

5. Об организации предоставления государственных и муниципальных услуг: федеральный закон от 27.07.2010 г. № 210-Ф3 (посл. ред. от 31.07.2020). - Текст: электронный // СПС «КонсультантПлюс»: [сайт]. - URL: http://www.consultant.ru/document/ cons_doc_LAW_61798/ (дата обращения: 06.09.2020).

6. О персональных данных: федеральных закон от 27.07.2006 г. № 152-Ф3 (посл. ред. от 24.02.2020). - Текст: электронный // CПС «КонсультантПлюс»: [сайт].- URL: http://www.consultant.ru/document/cons_doc__ LAW_61801/ (дата обращения: 06.09.2020).

7. Об электронной подписи: федеральный закон от 06.04.2011 г. № 63-Ф3 (посл. ред. от 01.07.2020). - Текст: электронный // CПС «КонсультантПлюс»: [сайт]. - URL: http://www.consultant.ru/document/ cons_doc_LAW_112701/ (дата обращения: 06.09.2020).

8. Об основных направлениях совершенствования системы государственного управления: Указ Президента РФ от 12.05.2012 г. № 601 (посл. ред. от 01.07.2020). - Текст: электронный // CПС «Гарант»: [сайт]. - URL: http://base.garant.ru/70170942/ (дата обращения: 06.09.2020).

9. Об утверждении государственной программы Российской Федерации «Информационное общество» (2011-2020 годы): Постановление Правительства РФ от 15.04.2014 г. № 313 (посл. ред. от 21.08.2020). - Текст: электронный // СПС «КонсультантПлюс»: [сайт]. - URL: http://www.consultant.ru/document/cons_doc_LAW_162184/ (дата обращения: 06.09.2020).

10. О Концепции развития механизмов предоставления государственных и муниципальных услуг в электронном виде: Распоряжение Правительства РФ от 25.12.2013 г. № 2516-р (посл. ред. от 13.10.2017). - Текст: электронный // СПС «КонсультантПлюс»: [сайт]. - URL: http://www.consultant.ru/document/cons_doc_LAW_156812/ (дата обращения: 06.09.2020).

11. О требованиях к предоставлению в электронной форме государственных и муниципальных услуг: Постановление Правительства РФ от 26.03.2016 г. № 236 (посл. ред. 
от 21.08.2020) // СПС «КонсультантПлюс»: [сайт]. - URL: http://www.consultant.ru/ document/cons_doc_LAW_195919/ (дата обращения: 06.09.2020).

12. Электронное правительство в РФ. - Текст: электронный // Министерство цифрового развития, связи и коммуникаций Российской Федерации: [сайт]. - URL: https://digital.gov.ru/ru/activity/statistic/rating/elektronnoe-pravitelstvo-v-rf/ (дата обращения: 01.09.2020).

\section{Транслитерация}

1. O federal'noj celevoj programme «Elektronnaya Rossiya (2002-2010 gody)»: postanovlenie Pravitel'stva RF ot 28.01.2002 № 65 (red. ot 09.06.2010). - Tekst: elektronnyj // SPS «Garant»: [sajt]. - URL: http://base.garant.ru/184120/ (data obrashcheniya: 06.09.2020).

2. Informacionnoe obshchestvo (2011-2020 gody). - Tekst: elektronnyj // SPS «Konsul'tantPlyus»: [sajt]. - URL: http://www.consultant.ru/document/Cons_doc_LAW_ 155198/d60fab9834a8f7ea1bad56bb17af05751937b2a3/ (data obrashcheniya: 06.09.2020).

3. Ob informacii, informacionnyh tekhnologiyah i o zashchite informacii: federal'nyj zakon ot 27.07.2006 g. № 149-FZ (posl. red. ot 03.04.2020). - Tekst: elektronnyj // SPS «Konsul'tantPlyus»: [sajt]. - URL: http://www.consultant.ru/document/cons_doc_LAW_61798/ (data obrashcheniya: 06.09.2020).

4. Ob organizacii predostavleniya gosudarstvennyh i municipal'nyh uslug: federal'nyj zakon ot 27.07.2010 g. № 210-FZ (posl. red. ot 31.07.2020). - Tekst: elektronnyj // SPS «Konsul'tantPlyus»: [sajt]. - URL: http://www.consultant.ru/document/ cons_doc_LAW_61798/ (data obrashcheniya: 06.09.2020).

5. O personal'nyh dannyh: federal'nyh zakon ot 27.07.2006 g. № 152-FZ (posl. red. ot 24.02.2020). - Tekst: elektronnyj // SPS «Konsul'tantPlyus»: [sajt]. - URL: http://www.consultant.ru/document/cons_doc_LAW_61801/ (data obrashcheniya: 06.09.2020).

6. Ob elektronnoj podpisi: federal'nyj zakon ot 06.04.2011 g. № 63-FZ (posl. red. ot 01.07.2020). - Tekst: elektronnyj // SPS «Konsul'tantPlyus»: [sajt]. - URL: http://www.consultant.ru/document/ cons_doc_LAW_112701/ (data obrashcheniya: 06.09.2020).

7. Ob osnovnyh napravleniyah sovershenstvovaniya sistemy gosudarstvennogo upravleniya: ukaz Prezidenta RF ot 12.05.2012 g. № 601 (posl. red. ot 01.07.2020). - Tekst: elektronnyj // SPS «Garant»: [sajt]. - URL: http://base.garant.ru/70170942/ (data obrashcheniya: 06.09.2020).

8. Ob utverzhdenii gosudarstvennoj programmy Rossijskoj Federacii «Informacionnoe obshchestvo»(2011-2020 gody): postanovlenie Pravitel'stva RF ot 15.04.2014 g. № 313 (posl. red. ot 21.08.2020). - Tekst: elektronnyj // SPS «Konsul'tantPlyus»: [sajt]. - URL: http://www.consultant.ru/document/cons_doc_LAW_162184/ (data obrashcheniya: 06.09.2020)

9. O Koncepcii razvitiya mekhanizmov predostavleniya gosudarstvennyh i municipal'nyh uslug v elektronnom vide: rasporyazhenie Pravitel'stva RF ot 25.12.2013 g. № 2516-r (posl. red. ot 13.10.2017). - Tekst: elektronnyj // SPS «Konsul'tantPlyus»: [sajt]. - URL: http://www.consultant.ru/document/cons_doc_LAW_156812/ (data obrashcheniya: 06.09.2020)

11. O trebovaniyah $\mathrm{k}$ predostavleniyu $\mathrm{v}$ elektronnoj forme gosudarstvennyh i municipal'nyh uslug: postanovlenie Pravitel'stva RF ot 26.03.2016 g. № 236 (posl. red. ot 21.08.2020) // SPS «Konsul'tantPlyus»: [sajt]. - URL: http://www.consultant.ru/ document/cons_doc_LAW_195919/(data obrashcheniya: 06.09.2020). 
12. Elektronnoe pravitel'stvo v RF. - Tekst: elektronnyj // Ministerstvo cifrovogo razvitiya, svyazi i kommunikacij Rossijskoj Federacii: [sajt]. - URL: https://digital. gov.ru/ru/activity/statistic/rating/elektronnoe-pravitelstvo-v-rf/ (data obrashche-niya: 01.09.2020).

(C) А.С. Давиденко, 2020

Для цитирования: Давиденко А.С. Концепция электронного правительства и цифровизация политической системы // Территория новых возможностей. Вестник Владивостокского государственного университета экономики и сервиса. - 2020. - Т. 12, № 4. C. 30-38.

For citation: Davidenko A.S. E-government concept and digitalization of the political system, The Territory of New Opportunities. The Herald of Vladivostok State University of Economics and Service, 2020, Vol. 12, № 4, pp. 30-38.

DOI dx.doi.org/10.24866/VVSU/2073-3984/2020-4/030-038

Дата поступления: 23.11.2020. 